\title{
Zn-Mg and Zn-Ag degradation mechanism under biologically relevant conditions
}

Karin Beaussant Törne ${ }^{1,2}$, Fareed Ashraf Khan ${ }^{3}$, Andreas Örnberg ${ }^{2}$, Jonas Weissenrieder ${ }^{1, *}$

1. Material Physics, Department of Applied Physics, KTH Royal Institute of Technology, Electrum 229, 16440 Kista, Sweden

2. Abbott, 177 E County Rd B, St. Paul, MN 55117, USA

3. Materials Science and Engineering, KTH Royal Institute of Technology, Stockholm, Sweden

*Corresponding author: jonas@kth.se

Keywords: zinc(Zn), alloy, magnesium (Mg), silver (Ag), in vitro, electrochemical, impedance spectroscopy (EIS), biodegradable metal

\section{Abstract}

Zinc alloys form a promising new class of biodegradable metals that combine suitable mechanical properties with the favorable degradation properties of pure zinc. However, the current understanding of the influence of alloying elements on the corrosion of zinc alloys, in biologically relevant media, is limited. We studied the degradation of three alloys, Zn 4 wt\% Ag, Zn 0.5 wt\% Mg and Zn 3 wt\% Mg by in situ electrochemical impedance spectroscopy (EIS). After exposure for $1 \mathrm{th}$ or 30 days the samples were characterized by infrared spectroscopy and scanning electron microscopy (SEM). The presence of secondary phases in the alloy microstructure induced selective corrosion and increased degradation rate. An increase in surface inhomogeneity was evident by EIS analysis both at short (hours) as well as long immersion times (days). The microgalvanic corrosion of the $\mathrm{Zn}$-Ag alloy resulted in enrichment of the $\mathrm{AgZn}_{3}$ phase at the sample surface. The enrichment of Ag and potential release of $\mathrm{AgZn} \mathrm{n}_{3}$ particles may result in complications during the tissue regeneration. The Zn-Mg alloy surface was depleted of the Mg-rich phase after 8-12 days. The selective dissolution caused local precipitation of 
corrosion products and a thicker corrosion layer with larger pore size consistent with increased corrosion rate.

\section{Introduction}

For more than a decade biodegradable metals have been proposed as a potential material for temporary implants.(1) The combination of a simple degradation profile and mechanical strength are properties that renders biodegradable metals attractive for future cardiovascular and orthopedic applications.(2, 3) Currently permanent metallic implants are also used for applications where the implant is only necessary during a healing and remodeling phase. A permanent implant may cause late adverse effect and require a second surgery to remove the implant. $(3,4)$ Degradable implants can reduce cost and more importantly improve the patient quality of life by avoiding explantation surgery. Iron and magnesium alloys were first suggested due to their low toxicity.(1) Magnesium alloys also possess a favorable mechanical hardness close to the hardness of cortical bone.(3) However in vivo studies showed that the corrosion rate of magnesium is too fast for most applications. $(1,5)$ Further magnesium degradation often produces copious amounts of hydrogen gas.(1) Hydrogen gas bubbles formed in the vicinity of the implant surface may complicate the healing process .(5) Hydrogen may also be absorbed by the remaining magnesium implant which can result in hydrogen embrittlement and premature failure of load bearing implants.(6) Iron on the other hand degrades too slowly for many applications and produces voluminous corrosion products causing an increase of the volume of the implant. $(7,8)$

Zinc was recently suggested as an alternative degradable metal or alloy base. $(9,10)$ The toxicity of zinc is higher than that of iron or magnesium and concern have therefore been raised regarding its biocompatibility. Cytotoxicity studies have shown a reduced viability of vascular smooth muscle cells grown in zinc alloy extracts. $(11,12)$ However, numerous in vivo studies show thin thickness of neointimal tissue and tissue regeneration. $(4,11)$ Vojtech et al. estimated the daily release from a zinc bone screw to be $1.5 \mathrm{mg} /$ day.(9) This can be compared to the $2-3 \mathrm{~g}$ of zinc contained in the human body and the recommended dietary allowance of $15 \mathrm{mg} /$ day. $(9,13,14)$ The corrosion rate of pure zinc appeared to be ideal for cardiovascular stent and bone fixation applications. $(9,10)$ Both in vivo and in 
vitro studies have determined the corrosion rate to be in the order of tens of microns per year, between the degradation rates of magnesium and iron. $(9,10,15)$ Pure zinc, however, is soft and exhibit relatively low tensile strength. In order to improve the mechanical properties of zinc researches have suggested several alloying elements. Li et al demonstrated that Mg, Ca and Sr are suitable candidates that may result in alloys with increased strength and ductility compared to pure zinc.(11) Further improvements were obtained with ternary alloys Zn-Mg-X where $\mathrm{x}$ is $\mathrm{Ca}$ or $\mathrm{Sr}$.(16) More recently ZnAg alloy was shown to possess high mechanical strength as well as superplasticity.(17) Current knowledge suggests Zinc alloys to be a promising new class of biodegradable metals. However there is still a lack of understanding of what effect alloying has on the corrosion mechanism and temporal evolution of the surface properties in a biological relevant environment. It is of specific interest to establish how the microstructure of the alloys influence the interface properties of the corroding surface, at different times in the degradation process and how it may be at variance from that of pure zinc samples. In the current study we employ electrochemical techniques to study the initial (hours) and long term (30 days) degradation mechanism of two Zn-Mgalloys and one Zn-Ag alloy and compare the results to pure zinc samples. Through the use of electrochemical impedance spectroscopy, EIS, which allows for in situ characterization of the corroding interface during immersion, new information of the effect of alloying on the biodegradation of zinc may be obtained. By characterizing the surface with EIS over a long term it is possible to detect time dependent changes of the interface and the corrosion mechanism. Together with careful ex situ examination, including scanning electron microscopy (SEM) of the surface and of cross sections, a detailed description of the interfaces and corrosion mechanisms is provided.

\section{Materials and methods}

\section{Materials fabrication and characterization}

The alloys were prepared by melting pure $\mathrm{Zn}$ and either $\mathrm{Mg}$ or Ag under ambient conditions at $550{ }^{\circ} \mathrm{C}$ for 20 minutes. The melt was casted at room temperature into rods of $12 \mathrm{~mm}$ in diameter. Cast rods of pure $\mathrm{Zn}$ were prepared as reference samples using the same process. The targeted composition of the alloys was 0.5 and 3 ut\% of Mg and 4 ut\% Ag, here denoted as Zn0.5Mg, Zn3Mg and Zn4Ag respectively. The compositions were chosen as previous studies have shown them to be of particular interest as degradable alloys. Alloys with 0.5 wt \% of Mg have been shown to possess a suitable combination of strength and elasticity and 3 wt \% is a eutectic point of the Zn-Mgsystem.(9, 18, 19) 
For the Ag alloys, Liu et al demonstrated that a minimal grain size is obtained by alloying with 4 wt \% Ag, which implies higher strength.(20)

Microstructural characterization was performed by optical microscopy and scanning electron microscopy, SEM, Carl Zeiss ${ }^{\mathrm{TM}}$ AG Ultra 55 with an Oxford Instrument ${ }^{\mathrm{TM}}$ INCA $^{\mathrm{TM}}$ PentaFET x3 energy-dispersive X-ray spectroscopy (EDX) analyzer, on samples polished according to ASTM Guide E3-11.

The composition of the alloys was analyzed by inductively coupled plasma optical emission spectroscopy (ICP-OES), Agilent ${ }^{\mathrm{TM}}$ 720. The compositions are presented in Table 1.

The hardness of the samples was measured using a Vickers indenter with $4.9 \mathrm{~N}$ (500 g-F) load, according to ASTM E384-11.

\section{Electrochemical characterization}

A three electrode flat cell was used for al electrochemical measurements. The reference electrode was an $\mathrm{Ag} / \mathrm{AgCl}$ saturated $\mathrm{KCl}$ electrode. All potentials are given relative to this reference electrode. The counter electrode was a large surface area Pt mesh.

Initial corrosion rates were obtained from potentiodynamic polarization scans (PDP), performed after $30 \mathrm{~min}$ immersion, from $-20 \mathrm{mV}$ to $+250 \mathrm{mV}$ vs the open circuit potential (OCP) at a scan rate of 0.16 $\mathrm{mVs}^{-1}$, according to ASTM G5-14.(21)

A long term (30 days) immersion study was performed in Ringer's solution at $37^{\circ} \mathrm{C}$. Three samples each of the alloys and cast zinc was evaluated. Previous studies showed Ringer's solution to be the more suitable model electrolyte for long term in vitro studies of Zn biodegradation.(15) $300 \mathrm{ml}$ of buffer was used per sample and $132 \mathrm{ml}$ was continuously exchanged, using a peristaltic pump, every $24 \mathrm{~h}$ to prevent changes in $\mathrm{pH}$ or increasing concentration of $\mathrm{Zn}^{2+}$. Electrochemical impedance spectroscopy (EIS) was measured at regular intervals during the immersion time. To avoid irreversible changes to the surface a low perturbation amplitude of $2 \mathrm{mV}$ was employed.(15) A frequency interval between $100^{\prime} 000$ and $0.1 \mathrm{~Hz}$ was chosen as measuring at lower frequencies may induce irreversible surface modifications even at these low applied perturbation amplitudes.

Following the immersion the sample surface was characterized by SEM and the composition of the corrosion product was determined by Fourier transform infrared spectroscopy (FTIR), Thermo 
Scientific $^{\mathrm{TM}}$ Nicolet $^{\mathrm{TM}}$ iS $^{\mathrm{TM}}$ 10. After initial examination of the sample surface the corrosion product was removed by cleaning in $12 \%$ ammonia solution, according to ASTM G1 (22), of two of the three samples to investigate the underlying metallic surface. Polished samples were also immersed in the ammonia solution and investigated by SEM to confirm that the cleaning process only removed the corrosion product and does not affect the metallic surface. The third sample was used to prepare cross sections by mounting in epoxy resin and polishing down to the desired depth. Samples were also immersed in Ringer's solution for $1 \mathrm{~h}$ for short term microscopic evaluation of the surface structure.

\section{Results}

\section{Composition and microstructure}

The chemical compositions of the zinc alloys as determined by ICP-OES are presented in Table 1.The cast zinc samples exhibit grains of 20-50 microns in width, Figure $1 \mathrm{a}$. Micropores formed during the casting process were observed in the cast zinc samples as well as the alloys (selected pores are indicated by arrows in Figure 1). The addition of the alloying elements resulted in a significant grain refinement and formation of secondary phases. The Zn4Ag samples features a dendritic structure, Figure $1 \mathrm{~b}$ with grains 1-10 microns wide and 10 - 50 microns long. Liu et al characterized the grain refinement in $\mathrm{Zn}-\mathrm{Ag}$ alloys as due to initial formation of $\varepsilon-\mathrm{AgZn} \mathrm{n}_{3}$ phase which serves as nucleation sites for the $\eta-Z n$ phase in a peritectic solidification reaction.(20) The insert in Figure $1 \mathrm{~b}$ shows a high magnification SEM image of a $\mathrm{AgZn}_{3}$ particle. $(17,20) \mathrm{The} \mathrm{Zn} 0.5 \mathrm{Mg}$ microstructure was characterized by primary Zn grains, (light areas) approximately $20 \mu \mathrm{m}$ in size and precipitates of an Mg containing eutectic phase at the grain boundaries, (dark areas) Figure $1 \mathrm{c}$. The second, eutectic, phase has been assigned as $\mathrm{Mg}_{2} \mathrm{Zn}_{11 .}$.(23) The microstructure of the $\mathrm{Zn} 3 \mathrm{Mg}$ alloy exhibited smaller, $<10 \mu \mathrm{m}$, $\mathrm{Zn}$ grains and an increased concentration of $\mathrm{Mg}_{2} \mathrm{Zn}_{11}$ phase, Figure $1 \mathrm{~d}$. Microhardness analysis showed increasing hardness of the alloys relative to the cast zinc. The hardness of the $\mathrm{Zn}-\mathrm{Mg}$ alloys increased with increasing Mg content and the Zn4Ag alloy had a similar hardness to the Zn0.5Mgalloy, Figure 2 .

\section{Potentiodynamic polarization (PDP)}

PDP analysis of cast zinc and zinc alloy samples after 30 min immersion in Ringer's solution are shown in Figure 3 a. A decrease in corrosion potential of the alloys compared to the cast $\mathrm{Zn}$ was observed. Initial corrosion rates were calculated from Tafel fits, Figure $3 \mathrm{~b}$. There was no statistically significant 


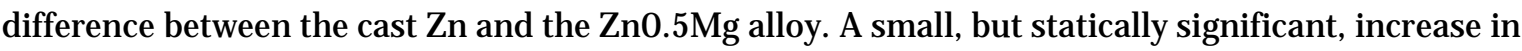
corrosion rate was observed for the Zn3Mg and Zn4Ag alloy.

\section{Open circuit potential (OCP)}

The development of the OCP during the 30 days immersion study is presented in Figure $4 \mathrm{a}-\mathrm{d}$. The initial OCP of the $\mathrm{Zn} 0.5 \mathrm{Mg}$ and $\mathrm{Zn} 3 \mathrm{Mg}$ alloys was shifted cathodically compared to the cast zinc. This shift is expected as magnesium has a more cathodic OCP than zinc. The $\mathrm{Mg}_{2} \mathrm{Zn}_{11}$ phase is therefore expected to have a more cathodic potential than the Zn phase. The initial OCP of the Zn4Ag alloy was also shifted cathodically compared to $\mathrm{Zn}$ during the first hour of immersion but increased rapidly to values similar to $\mathrm{Zn}$ (not shown). During the immersion period the OCP of all samples increased anodically from between $-1.06 \mathrm{~V}$ and $-1.03 \mathrm{~V}$ to between $-0.99 \mathrm{~V}$ and $-0.93 \mathrm{~V}$ suggesting the buildup of a protective corrosion layer. At long immersion times no difference in OCP could be observed between $\mathrm{Zn}$ and the $\mathrm{Zn}$ alloys.

\section{Electrochemical impedance spectroscopy}

Representative Bode plots of the impedance response of the interface at selected time points during the 30 day immersion of the cast zinc and zinc alloy samples are presented in Figure $5 \mathrm{a}-\mathrm{d}$. The impedance at short immersion time of all samples show two apparent time constants. For the alloy samples the first time constant appears at $\sim 100 \mathrm{~Hz}$ and the second at $0.1-1 \mathrm{~Hz}$. However, the low frequency time constant of $\mathrm{Zn}$ was observed at slightly higher frequencies, around $10 \mathrm{~Hz}$, Figure $5 \mathrm{a}$. The high and low frequency time constants have previously been ascribed to the charge transfer process and a diffusion process through a porous layer of corrosion product.(15, 24) For most of the samples the low frequency time constant was absent at long immersion times ( $>12$ days), indicating a breakdown of the protective corrosion product layer and an onset for localized corrosion. The time point at which the change in corrosion mechanism occurred seems stochastic, with no apparent trend between the alloys. For some samples (one cast zinc, one Zn0.5Mg and one Zn3Mg) the low frequency time constant remained present throughout the entire immersion period. This suggests that the breakdown of the corrosion product layer did not yet occur for these samples.

The impedance data with two time constants was fitted using the equivalent circuit in Figure 6 a. Constant phase elements was used rather than ideal capacitors to compensate for surface inhomogeneity.(25) $\mathrm{CPE}_{\mathrm{F}}$ describes the capacitance of the corrosion film. $\mathrm{R}_{\mathrm{p}}$ represents the resistance 
of the pores. $\mathrm{CPE}_{\mathrm{p}}$ describes the capacitance of the metal solution interface at the pore bottom. $\mathrm{R}_{\mathrm{ct}}$ describes the charge transfer resistance. The spectra consisting of one time constant were fitted using a Randles type equivalent circuit, Figure $6 \mathrm{~b}, \mathrm{CPE}_{\mathrm{DL}}$ describes the double layer capacitance. All fitted data are included in the supplementary information.

The capacitance of the corrosion film on cast zinc samples initially decreased with time, from 60 to $20 \mu \mathrm{s}^{n} \Omega^{-1} \mathrm{Cm}^{-2 t}$, suggesting a growing corrosion layer. After a few days of immersion times the trend reversed and the capacitance increased, from $20-100 \mu \mathrm{s}^{n} \Omega^{-1} \mathrm{~cm}^{-2}$ potentially due to increasing surface roughness. The capacitance of the film of corrosion products on cast zinc samples was roughly one order of magnitude ( $\left.10-100 \mu \mathrm{s}^{\eta} \Omega^{-1} \mathrm{Cm}^{-2}\right)$ lower compared to the alloy samples $\left(\sim 400 \mu \mathrm{s}^{\eta} \Omega^{-1} \mathrm{~cm}^{-2}\right)$ at all time points. The exponential term $\eta$ of the $\mathrm{CPE}$ was 0.7-0.9 for both cast zinc and the alloys.

The pore resistance of cast zinc increased over the first days from $\sim 30$ - $100 \Omega \mathrm{cm}^{-2}$ to $\sim 500$ $1000 \Omega \mathrm{cm}^{-2}$ and stabilized thereafter. However large fluctuations with time were observed. Increasing pore resistance suggests growing pore length, i.e. increasing film thickness. The fluctuations with time can be explained by cycles of formation and detachment of the corrosion layer. The $R_{p}$ of the alloys was lower compared to cast zinc suggesting a thinner layer or increased pore size. The Zn4Ag alloy stabilized at $100 \Omega \mathrm{cm}^{-2}$ and occasionally increased to $\sim 400 \Omega \mathrm{cm}^{-2}$. In a similar way the $\mathrm{R}_{\mathrm{p}}$ of the $\mathrm{Zn} 0.5 \mathrm{Mg}$ alloy stabilized at 40 - $200 \Omega \mathrm{cm}^{-2}$. Intermittently the $\mathrm{R}_{\mathrm{p}}$ increase to $400 \Omega \mathrm{cm}^{-2}$, a behavior consistent with cycles of formation and detachment of the corrosion layer. The Zn3Mg alloy demonstrated the lowest $R_{p}$, which remained below $100 \Omega \mathrm{cm}^{-2}$.

Similar to the film capacitance the $\mathrm{CPE}_{\mathrm{p}}$ for cast zinc samples stabilized at lower values ( 300 - 1000 $\left.\mu \mathrm{s}^{\eta} \Omega^{-1} \mathrm{Cm}^{-2}\right)$ compared to the $\mathrm{Zn}$ alloys $\left(10^{\prime} 000-20^{\prime} 000 \mu \mathrm{s}^{\mathrm{\eta}} \Omega^{-1} \mathrm{Cm}^{-2}\right)$. The increased capacitance of the alloys is consistent with larger pore size and with higher porosity corresponding to a larger surface area. The exponential term $\eta$ was $\sim 0.5$ consistent with a diffusion controlled process.

The resistance related to the charge transfer resistance $R_{c t}$ of cast zinc increased during the first days to $\sim 1000 \Omega \mathrm{cm}^{-2}$ suggesting increasing protection with time. The $\mathrm{R}_{\mathrm{ct}}$ of $\mathrm{Zn} 0.5 \mathrm{Mg}$ decreased initially to 20-70 $\Omega \mathrm{cm}^{-2}$ after 2-8 days and then increased to reach $\sim 400 \Omega \mathrm{cm}^{-2}$ after 10 days. $\mathrm{R}_{\mathrm{D}}$ of Zn3Mgdecreased to $150 \Omega \mathrm{cm}^{-2}$ after 2-8 days and subsequently increased to around $500 \Omega \mathrm{cm}^{-2}$. $R_{D}$ $\mathrm{Zn} 4 \mathrm{Ag}$ remained around $200 \Omega \mathrm{cm}^{-2}$ for the majority of the immersion time. 


\section{Ex situ examination}

\section{FTIR}

The vibration modes present in the FTIR spectra obtained from the alloys after immersion did not differ from cast zinc, implying a similar chemical composition of the majority of the corrosion product of all samples, a hydrated carbonate. Figure 7 shows a representative spectrum obtained from a $\mathrm{Zn} 0.5 \mathrm{Mg}$ sample. The strong peak at $3350 \mathrm{~cm}^{-1}$ corresponds to $\mathrm{H}_{2} \mathrm{O}$ stretching vibrations. The four bands at 1550, 1490, 1420 and $1390 \mathrm{~cm}^{-1}$ are assigned to antisymmetric $\mathrm{v}_{3} \mathrm{CO}_{3}{ }^{2-}$ modes. The bands at 1040 and $940 \mathrm{~cm}^{-1}$ correspond to $\mathrm{OH}$ liberation modes. The sharp peak at $820 \mathrm{~cm}^{-1}$ is ascribed to the out-of-plane $\mathrm{CO}_{3}{ }^{2-}$ bending mode. The two bands at 730 and 690 correspond to the $\mathrm{v}_{4} \mathrm{CO}_{3}{ }^{2-}$ modes . The spectra are overall in good agreement with literature spectra of hydrozincite $\mathrm{Zn}_{5}\left(\mathrm{CO}_{3}\right)_{2} \bullet(\mathrm{OH})_{6}$.(26)

\section{SEM after $1 \mathrm{~h}$ immersion}

SEM images of $\mathrm{Zn}$ samples exposed for $1 \mathrm{~h}$ showed a thin layer of corrosion product precipitated onto the surface, Figure 8 a. The surface of the alloys showed a non-uniform layer of corrosion product of similar structure but with pores (pore size: 1 - $10 \mu \mathrm{m}$ ) scattered over the surface. Figure 8b show an image of representative pores, indicated by the encircled areas, from a Zn3Mg sample. The dashed lines surrounds agglomerated corrosion product around one of the pits. The porous structure of the corrosion layer on Zn05Mg and Zn4Ag were similar to the corrosion layer on Zn3Mg and are not shown here.

SEM of cast zinc (30 days)

SEM images of the surface of cast zinc samples after 30 days immersion showed a thick compact layer of corrosion product, Figure 9 a. A structure with similar appearance as the grain microstructure with thinner corrosion product at the grain boundaries and thicker towards the center of the grains was observed. This structure suggests increased anodic oxidation at the grain boundaries and cathodic reduction and subsequent corrosion product precipitation at the grain center. In agreement with the FTIR results, EDS analysis confirmed the presence of carbon, oxygen and zinc. Some areas of the corrosion film were rich in defects and exposed deep pits, confirming the film breakdown suggested in the EIS results. Similar defects were observed on the alloy samples as well. After the corrosion product was removed, SEM images showed that the majority of the surface had a relatively smooth stratified structure, Figure 10 a. Deep (hundreds of $\mu \mathrm{m}$ ) pits, $1-2 \mathrm{~mm}$ wide were also observed confirming the 
presence of localized corrosion, insert in Figure 9 a. Cross sectional SEM images revealed a smooth homogenous coating $\sim 10 \mu \mathrm{m}$ thick, Figure 11 a.

\section{SEM of Zn4Ag (30 days)}

Parts of the surface of the Zn4Ag samples were covered by a thick corrosion product, shown in the insert in figure $9 \mathrm{~b}$. The majority of the surface was however only covered by a thin layer of corrosion product, Figure $9 \mathrm{~b}$. AgZn 3 particles were clearly visible in the surface structure, as indicated by the dashed lines in Figure 9b. EDS analysis detected low levels of $\mathrm{C}$ and $\mathrm{O}$ and high levels of $\mathrm{Zn}$ and $\mathrm{Ag}$ likely from the underlying metal. After the corrosion product was removed the surface structure demonstrated clear signs of microgalvanic corrosion with selective corrosion surrounding the more noble (Ag rich) AgZn $n_{3}$ particles, Figure $10 \mathrm{~b}$. The selective anodic dissolution sounding the $\mathrm{AgZn_{3 }}$ dendrites are indicated by dashed lines encircling the attack. However there was no sign of the large corrosion pits (in mm size) observed on the cast $\mathrm{Zn}$ samples. The cross sectional analysis showed a highly inhomogeneous surface with pores penetrating tens of microns down in the metal matrix, Figure $10 \mathrm{~b}$. There was no detectable corrosion layer on the areas which were not covered by the local thick precipitation of corrosion product. This suggests that any precipitated corrosion layer on these areas is thinner than $1 \mu \mathrm{m}$.

SEM of Zn0.5Mg and Zn3Mg (30 days)

The surface of $\mathrm{Zn} 0.5 \mathrm{Mg}$ samples after 30 days immersion showed a porous corrosion product, pore size $<1 \mu \mathrm{m}$ with local precipitates forming denser corrosion product, Figure $9 \mathrm{c}$. The insert is a magnification of the porous structure. EDS detected $\mathrm{C}$, $\mathrm{O}$ and $\mathrm{Zn}$ with no difference in elemental composition between the dense and porous corrosion product. The surface of Zn3Mg was covered by clusters of corrosion product which lump together to form ridges and pores a few microns in size Figure $9 \mathrm{~d}$. Millimeter wide pits due to localized corrosion similar to what was reported above for cast zinc samples were observed on both alloys. The cleaned samples surface had a layered structure similar to the cast zinc samples, Figure $9 \mathrm{c}$ and $\mathrm{d}$. Small pits, $<1 \mu \mathrm{m}$, indicated by arrows, were observed which were not observed on the cast zinc samples. The EDS analysis on the cleaned surfaces of both alloys detected only very low levels of magnesium on the sample surface. This Mg depletion suggests a selective dissolution of the Mg rich phases. The cross sections of $\mathrm{Zn0.5Mg}$ demonstrated an uneven surface with micro crevices filled with corrosion product $\sim 30 \mu \mathrm{m}$ deep, Figure $10 \mathrm{c}$. The cross 
sections of Zn3Mg also partly demonstrated a thick corrosion layer as well as some areas covered by a thinner more irregular corrosion product as seen in Figure $10 \mathrm{~d}$.

\section{Discussion}

In agreement with previously reported results the introduction of alloying elements ( $\mathrm{Mg}$ and $\mathrm{Ag}$ ) to zinc increases the hardness of the metal by both grain refinement and the introduction of secondary phases.(19) Increased hardness suggests increased strength and alloying appears to be a possible route to reach the desired mechanical properties of a biodegradable metallic implant. However the secondary phases appear to cause selective or microgalvanic corrosion due to potential differences between the primary $\mathrm{Zn}$ phase and the Ag/ Mg rich phases. The selective corrosion mechanism may result in changing mechanical properties and biocompatibility of an implant during its degradation.

The selective corrosion of the $\mathrm{Zn}$ phase in the Zn4Ag alloys is directly observed in the SEM analysis, where the $\mathrm{AgZn}$ dendrites function as cathodic sites and the surrounding areas suffers increased anodic dissolution, Figure 9-11. The local precipitation of corrosion product seen in the insert in Figure $9 \mathrm{~b}$ can be linked to an uneven distribution of $\mathrm{AgZn}_{3}$ particles from to the casting process. The corrosion mechanism is schematically illustrated in Figure 12 where more corrosion product is expected to precipitate on cathodic areas with denser population of $\mathrm{AgZ} \mathrm{n}_{3}$ particles. The selective dissolution of $\mathrm{Zn}$ will result in an enrichment of the Ag-rich phase at the implant surface and as the corrosion proceed in a potential release of $\mathrm{ZnAg}_{3}$ particles. Such change in interface properties should be considered when evaluating the cyto- and biocompatibility of Zn-Ag alloys. Silver in itself is cytotoxic but low amounts of silver as an alloying element have been suggested to be beneficial to induce antibacterial properties to implants.(27) Enrichment of silver on the surface with time may however change the initially beneficial antibacterial properties to cytotoxic properties as the silver concentration increases. Such changes may complicate the healing process. The initial fraction of $\mathrm{AgZn}_{3}$ is estimated to 3 volume \% (from an initial composition of $4 \mathrm{wt} \% \mathrm{Ag}$ ). As the implant degrades the fraction of $\mathrm{AgZn}_{3}$ will increase. Future studies on the biocompatibility and cytotoxicity on pure $\mathrm{AgZn}_{3}$ is therefore of interest. The increasing surface area should also be considered as it may increase the amount of $\mathrm{Zn}$ released per unit time, relative to a pure $\mathrm{Zn}$ implant, and may reduce the lifespan of 
the implant. The selective dissolution of Mg in magnesium alloys is associated with stress corrosion cracking (SCC). (6) An evaluation of the sensitivity of Zn-Ag alloys to SCC would hence also be of interest when further evaluating this new class of biodegradable alloys.

The SEM images of the Zn-Mg alloys also suggested micro galvanic corrosion, Figure 8-11. A schematic illustration of the corrosion mechanism is provided in Figure $12 \mathrm{~b}$. Unlike Zn4Ag the Mg rich secondary phase is subjected to anodic dissolution and the surrounding $\mathrm{Zn}$ phase constitute the cathode areas. This results in selective dissolution of the $\mathrm{Mg}$ rich phase and removal of $\mathrm{Mg}$ from the sample surface. The rate of dissolution and release of $\mathrm{Zn}^{2+}$ and $\mathrm{Mg}^{2+}$ increase locally at the anodic areas. This can be observed in Figure $8 \mathrm{~b}$ where pores form at anodic areas and precipitation of corrosion product occur on the surrounding cathodic areas. The micron sized pits observed on the cleaned samples, Figure $10 \mathrm{c}$ and d are of similar size and may be traces after Mg rich particles. Surrounding the anodic areas are cathodic areas with increased precipitation of corrosion product. The local precipitation and agglomeration of corrosion product as observed in Figure 8b will form the denser corrosion product at loner immersion times as observed on Zn0.5Mg in Figure $9 \mathrm{c}$. The microstructure of $\mathrm{Zn} 3 \mathrm{Mg}$ is mainly eutectic, Figure $1 \mathrm{~d}$, with a very even and fine dispersion of $\mathrm{Zn}$ and $\mathrm{Mg}_{2} \mathrm{Zn}_{11}$. The fine distribution of cathodic sites $(\mathrm{Zn})$ and local precipitation of corrosion product causes the stratified structure of the corrosion product, Figure $9 \mathrm{~d}$.

The initial corrosion rate of Zn4Ag was increased compared to cast zinc in agreement with the observed microgalvanic corrosion, Figure 3. These results supports the previously reported increase in corrosion rate with increasing Ag content by Sikora-J asinska et al.(17) The alloying of zinc with low amounts ( $0.5 \mathrm{wt} \%$ ) of Mg did shift the initial OCP anodically, suggesting increased surface reactivity but no significant increased corrosion rate was observed in the PDP measurements. However, when the amount of $\mathrm{Mg}$ was increased to $3 \mathrm{wt} \%$ an increase in initial corrosion rate similar to $\mathrm{Zn} 4 \mathrm{Ag}$ was observed. Previous studies have reported decreased corrosion rates for Zn3Mg alloys due to increased stability of the oxide layer. $(19,28)$ However, these studies were performed in $\mathrm{PO}_{4}^{3-}$ containing solutions which may result in decreased corrosion rates due to formation of a protective layer of phosphates.(29) Such phosphate protection has not been shown to occur in vivo $(15,30,31)$ and therefore corrosion rate assessment in phosphate solutions may not be considered as representative. Ringer's solution, which was used in this study, does not contain $\mathrm{PO}_{4}{ }^{2-}$ and therefore provides a better model of the in vivo situation.(15) 
The impedance measurements of both cast zinc and the alloys indicated the buildup and break down of a protective layer of corrosion products, Figure 5. The breakdown is indicated by the absence of a low frequency time constant at long immersion times which occurred after 12 to 30 days. The interpretation agrees with the localized corrosion observed in the SEM images as seen in the insert in Figure 9a. The breakdown may be initiated by local inhomogeneities such as the microspores observed in the microstructure, Figure 1. Further processing of the alloy by for example extrusion can homogenize the structure and minimize defects which would postpone the breakdown of the corrosion layer.

The analysis of the impedance data revealed increased capacitance for the alloys compared to cast zinc samples. Similar high capacitance have previously been reported for $\mathrm{Zn}-\mathrm{Al}-\mathrm{RE}$ alloys.(24) Such high capacitances are typically associated with microporous surface structures and large surface areas. Micropores were observed on the alloy surfaces already after $1 \mathrm{~h}$ of exposure, Figure $8 \mathrm{~b}$. At long immersion times the microporous structure of the corrosion product on the $\mathrm{Zn}-\mathrm{Mg}$ alloys, Figure $9 \mathrm{c}-\mathrm{d}$ is clearly visible and validates the impedance analysis. The surface of $\mathrm{Zn}$ - Ag after $1 \mathrm{~h}$ exposure also demonstrated micropores that may be linked to the increased capacitance. At long immersion times the high capacitance of Zn4Ag is however better rationalized by the large increase in surface area due to the selective dissolution. The impedance results demonstrate that already after $1 \mathrm{~h}$ exposure the selective corrosion of the alloys produces a less homogenous and more reactive surface compared to the cast zinc samples.

The initial charge transfer resistance, $R_{\mathrm{ct}}$ and pore resistance, $\mathrm{R}_{\mathrm{p}}$, of all the alloys were similar to cast zinc. However $\mathrm{R}_{\mathrm{ct}}$ and $\mathrm{R}_{\mathrm{p}}$ decreased over the first days to reach a minimum after 2-8 days and stabilized at lower values compared to cast zinc at long immersion times. The initial decrease is assigned to the in microscopy observed increase in surface area as well as the inhomogeneity of the surface from the selective dissolution. The increase of $\mathrm{R}_{\mathrm{ct}}$ of the $\mathrm{Zn}-\mathrm{Mg}$ after 12 days may be rationalized as the complete depletion of the $\mathrm{Mg}$ rich phase at the surface, i. e. only very limited amounts remains after $\sim 12$ days. The lower resistance compared to cast zinc can also be explained by an increase in real surface area. However, $R_{c t}$ is a measure of the resistance to oxidation from the metallic state to the ionic state such that a decrease in $\mathrm{R}_{\mathrm{ct}}$ will be consistent with increased oxidation due to the microgalavinc corrosion induced by the potential difference between the two phases present at the surface. The microgalvanic corrosion and decreasing $R_{p}$ is consistent with observed thin 
corrosion layer on the Zn4Ag alloy, Figure 9b, and increased porosity in the Zn-Mg alloys, Figure $9 \mathrm{c}$ and $\mathrm{d}$.

\section{Conclusions}

The corrosion properties of zinc alloys, $\mathrm{Zn} 4 \mathrm{Ag}, \mathrm{Zn} 0.5 \mathrm{Mg}$ and $\mathrm{Zn} 3 \mathrm{Mg}$ were evaluated by electrochemical techniques, PDP and EIS, and ex situ SEM and FTIR. An increase in corrosion rate of the alloys compared to cast zinc was observed in the PDP measurements. The impedance analysis suggested the presence of a porous corrosion film influencing the corrosion of the alloys. After $1 \mathrm{~h}$ immersion the impedance results show the surface of alloy samples to be less homogeneous than the cast zinc samples. At long immersion times the $\mathrm{R}_{\mathrm{ct}}$ of the alloys were lower compared to cast zinc suggesting continued increased corrosion. The lower $R_{c t}$ is consistent with the microgalvanic corrosion observed in the SEM analysis. The microgalvanic corrosion of Zn4Ag caused a selective dissolution of $\mathrm{Zn}$ and enrichment of $\mathrm{AgZn_{3 }}$ at the sample surface during immersion. Such enrichment of Ag at the interface may induce problematic cytotoxic effects in a clinical situation and influence the tissue regeneration process. Future studies of the biocompatibility of $\mathrm{AgZn} \mathrm{n}_{3}$ would therefore be of interest for assessing the suitability of $\mathrm{Zn}$-Ag based degradable metals. Selective dissolution of $\mathrm{Mg}$ based alloys is known to induce stress corrosion cracking. Investigations of the sensitivity of $\mathrm{Zn}$-Ag alloys to SCC would therefor also be of importance. The $\mathrm{Zn}-\mathrm{Mg}$ alloys on the other hand demonstrated a depletion of $\mathrm{Mg}$ at the surface after $\sim 12$ days and increased corrosion resistance. Although the effect of alloying on the average corrosion rate was small the micro galvanic corrosion induces significant local corrosion that may result in premature failure of the implant. The change in surface composition over time (due to the selective dissolution) raises concerns for the biocompatibility. Such effects should be considered when designing new materials and the presence of secondary phases should be minimized.

\section{Acknowledgements}

Abbott and the Swedish research council are acknowledged for their financial support. The authors would also like to acknowledge David Chmielewski for assistance with the micro hardness test and Nathan Freshour for assistance with the ICP-OES measurements. Hasse Fredriksson is gratefully acknowledged for assistance with the casting process.

\section{References}


1. Zheng YF, Gu XN, Witte F. Biodegradable metals. Materials Science \&Engineering R-Reports. 2014;77:1-34.

2. Bowen PK, Drelich J , Goldman J . A new in vitro-in vivo correlation for bioabsorbable magnesium stents from mechanical behavior. Materials Science \& Engineering C-Materials for Biological Applications. 2013;33(8):5064-70.

3. Staiger MP, Pietak AM, Huadmai J , Dias G. Magnesium and its alloys as orthopedic biomaterials: A review. Biomaterials. 2006;27(9):1728-34.

4. Bowen PK, Shearier ER, Zhao S, Guillory RJ, Zhao F, Goldman J, et al. Biodegradable Metals for Cardiovascular Stents: from Clinical Concerns to Recent Zn-Alloys. Advanced Healthcare Materials. 2016;5(10):1121-40.

5. Witte F, Hort N, Vogt C, Cohen S, Kainer KU, Willumeit R, et al. Degradable biomaterials based on magnesium corrosion. Current Opinion in Solid State \& Materials Science. 2008;12(5-6):6372.

6. Winzer N, Atrens A, Song GL, Ghali E, Dietzel W, Kainer KU, et al. A critical review of the stress corrosion cracking (SCC) of magnesium alloys. Advanced Engineering Materials. 2005;7(8):65993.

7. Pierson D, Edick J, Tauscher A, Pokorney E, Bowen P, Gelbaugh J , et al. A simplified in vivo approach for evaluating the bioabsorbable behavior of candidate stent materials. J ournal of Biomedical Materials Research Part B-Applied Biomaterials. 2012;100B(1):58-67.

8. Peuster M, Hesse C, Schloo T, Fink C, Beerbaum P, von Schnakenburg C. Long-term biocompatibility of a corrodible peripheral iron stent in the porcine descending aorta. Biomaterials. 2006;27(28):4955-62.

9. Vojtech D, KubasekJ, Serak J, Novak P. Mechanical and corrosion properties of newly developed biodegradable Zn-based alloys for bone fixation. Acta Biomaterialia. 2011;7(9):3515-22.

10. Bowen PK, Drelich J , Goldman J . Zinc Exhibits Ideal Physiological Corrosion Behavior for Bioabsorbable Stents. Advanced Materials. 2013;25(18):2577-82.

11. Li HF, Xie XH, Zheng YF, Cong Y, Zhou FY, Qiu KJ , et al. Development of biodegradable Zn-1X binary alloys with nutrient alloying elements Mg, Ca and Sr. Scientific Reports. 2015;5:13.

12. Shearier ER, Bowen PK, He W, Drelich A, Drelich J, Goldman J , et al. In Vitro Cytotoxicity, Adhesion, and Proliferation of Human Vascular Cells Exposed to Zinc. ACS Biomaterials Science \&Engineering. 2016;2(4):634-42.

13. Beyersmann D. Homeostasis and cellular functions of zinc. Materialwissenschaft Und Werkstofftechnik. 2002;33(12):764-9.

14. Fosmire GJ . Zinc toxicity. American J ournal of Clinical Nutrition. 1990;51(2):225-7.

15. Törne K, Larsson M, Norlin A, Weissenrieder J . Degradation of zinc in saline solutions, plasma, and whole blood. J Biomed Mater Res Part B. 2015;00(00):000- .

16. Liu XW, Sun J K, Qiu KJ, Yang YH, Pu ZJ , Li L, et al. Effects of alloying elements (Ca and Sr) on microstructure, mechanical property and in vitro corrosion behavior of biodegradable $\mathrm{Zn}-1.5 \mathrm{Mg}$ alloy. J ournal of Alloys and Compounds. 2016;664:444-52.

17. Sikora-J asinska M, Mostaed E, Mostaed A, Beanland R, Mantovani D, Vedani M. Fabrication, mechanical properties and in vitro degradation behavior of newly developed ZnAg alloys for degradable implant applications. Materials Science and Engineering: C. 2017;77:1170-81.

18. Kubasek J, Vojtech D, J ablonska E, Pospisilova I, Lipov J , Ruml T. Structure, mechanical characteristics and in vitro degradation, cytotoxicity, genotoxicity and mutagenicity of novel biodegradable Zn-Mg alloys. Materials Science \& Engineering C-Materials for Biological Applications. 2016;58:24-35.

19. Mostaed E, Sikora-J asinska M, Mostaed A, Loffredo S, Demir AG, Preuitali B, et al. Novel Znbased alloys for biodegradable stent applications: Design, development and in vitro degradation. J ournal of the Mechanical Behavior of Biomedical Materials. 2016;60:581-602.

20. Liu ZL, Qiu D, Wang F, Taylor JA, Zhang MX. The grain refining mechanism of cast zinc through silver inoculation. Acta Materialia. 2014;79:315-26.

21. ASTM. ASTM G5-14 Standard Reference Test Method for Making Potentiodynamic Anodic Polarization Measurements. West Conshohocken, PA, USA: ASTM International; 2014.

22. ASTM. G1. Standard Practice for Preparing, Cleaning, and Evaluating Corrosion Test Specimens. West Conshohocken, PA: ASTM international; 2011.

23. Prosek T, Nazarov A, Bexell U, Thierry D, Serak J . Corrosion mechanism of model zincmagnesium alloys in atmospheric conditions. Corrosion Science. 2008;50(8):2216-31. 
24. Rosalbino F, Angelini E, Maccio D, Saccone A, Delfino S. Application of EIS to assess the effect of rare earths small addition on the corrosion behaviour of $\mathrm{Zn}-5 \% \mathrm{Al}$ (Galfan) alloy in neutral aerated sodium chloride solution. Electrochimica Acta. 2009;54(4):1204-9.

25. Orazem M, Tribollet B. Electrochemical Impedanace Spectroscopy. Hoboken, New J ersey: J ohn Wiely and Sons Inc.; 2008.

26. Stoilova D, Koleva V, Vassileva V. Infrared study of some synthetic phases of malachite (Cu$2(\mathrm{OH})(2) \mathrm{CO} 3)$-hydrozincite $(\mathrm{Zn}-5(\mathrm{OH})(6)(\mathrm{CO})(2))$ series. Spectrochimica Acta Part a-Molecular and Biomolecular Spectroscopy. 2002;58(9):2051-9.

27. Tie D, Feyerabend F, Muller WD, Schade R, Liefeith K, Kainer KU, et al. ANTIBACTERIAL BIODEGRADABLE Mg-Ag ALLOYS. European Cells \& Materials. 2013;25:284-98.

28. Dambatta MS, Kurniawan D, Sudin I, Yahaya B, Hermawan H. Influence of homogenization treatment on the degradation behavior of $\mathrm{Zn}$-3Mg alloy in simulated body fluid solution. Proceedings of the Institution of Mechanical Engineers Part L-J ournal of Materials-Design and Applications. 2016;230(2):615-9.

29. Aramaki $\mathrm{K}$. The inhibition effects of chromate-free, anion inhibitors on corrosion of zinc in aerated 0.5 M NaCl. Corrosion Science. 2001;43(3):591-604.

30. Törne K, Örnberg A, Weissenrieder J. The influence of buffer system and biological fluids on the degradation of magnesium. J Biomed Mater Res Part B. 2016.

31. Törne K, Örnberg A, Weissenrieder J. Influence of strain on the corrosion of magnesium alloys and zinc in physiological environments. Acta Biomaterialia. 2017;48:541-50. 


\section{Tables}

Table 1: Chemical composition of cast alloy samples (as determined by ICP-OES).

\begin{tabular}{|l|l|l|l|}
\hline Alloy & $\mathrm{Mg}[\mathrm{wt} \%]$ & $\mathrm{Ag}[\mathrm{wt} \%]$ & $\mathrm{Zn}[\mathrm{wt} \%]$ \\
\hline Zn0.5Mg & 0.62 & - & $\mathrm{Bal}$. \\
\hline Zn3Mg & 2.6 & - & Bal. \\
\hline Zn4Ag & - & 4.4 & Bal. \\
\hline
\end{tabular}

\section{Figure captions}

Figure 1: Optical micrographs of a) cast zinc sample with grain size of 20 - $50 \mu \mathrm{m}$, b) Zn4Ag sample with dendritic grain structure. Insert is a SEM image of the $\mathrm{AgZn}_{3}$ precipitates at high magnification. c) Zno.5Mg sample with $\eta$-Zn grains (bright areas) and eutectic phase (dark areas) at grain boundaries. d) Zn3Mg sample with high density of eutectic phase and only scattered Zn grains. The arrows indicate selected microporous defects from the casting procedure.

Figure 2: Vickers hardness of cast zinc ( $35 \pm 5.5 \mathrm{HV}$ ) and zinc alloys, $\mathrm{Zn} 0.5 \mathrm{Mg}(65 \pm 5.4 \mathrm{HV}), \mathrm{Zn} 3 \mathrm{Mg}$ $(127 \pm 8.2 \mathrm{HV})$ and $\mathrm{Zn} 4 \mathrm{Ag}(66 \pm 3.2 \mathrm{HV})$. Error bars indicates one standard deviation of seven measurements over three samples.

Figure 3: a) PDP analysis of zinc and zinc alloys in Ringer's solution after 30 min immersion. The black solid line is pure cast zinc, red dashed line Zn4Ag, green dotted line Zn3Mg and blue dashed dotted line Zn0.5Mg. b) Corrosion rates obtained by Tafel fit of the PDP analysis. Error bars indicate one standard deviation of three samples.

Figure 4: Development of OCP during immersion of samples in Ringer's solution over 30 days. a) cast zinc, b) Zn4Ag, c) Zn3Mg d) Zn0.5Mg.

Figure 5: EIS Bode plots of zinc alloys during 30 days immersion in Ringer's solution a) pure cast zinc b) Zn4Ag c) Zn0.5Mg d) Zn3Mg. $\square 1 \mathrm{~h} \bullet 10$ days $\Delta 20$ days $\nabla 30$ days. Filled symbols are the absolute impedance, empty symbols the phase angle, and solid lines indicate fitted data.

Figure 6: Equivalent circuits used to simulate the EIS data. a) Circuit describing a porous interface. Used for samples at short and medium immersion times $<\sim 12$ days, b) Randles circuit describing the surface after breakdown of the porous layer. Used at long immersion times $>\sim 12$ days

Figure 7: FTIR spectra of corrosion product on a $\mathrm{Zn} 0.5 \mathrm{Mg}$ sample. The spectra obtained from cast zinc and the other alloys exhibit the same modes and the overall spectral shape agrees well with hydrozincite $\mathrm{Zn}_{5}\left(\mathrm{CO}_{3}\right)_{2} \bullet(\mathrm{OH})_{6}$.[24]

Figure 8: SEM images of the corrosion product layer after $1 \mathrm{~h}$ exposure a) cast $\mathrm{Zn}$ with a homogeneous layer of corrosion products, b) Zn3Mg alloys exhibiting micropores in the corrosion layer, encircled areas, and aglomerated corrosionproduct, indicated by the dashed line. Similar pores and product were detected on the other alloy surfaces as well.

Figure 9: SEM images of sample surface after 30 days immersion. a) cast zinc with dense corrosion product b) Zn4Ag exhibiting a thin corrosion film, the dashed lines indicates the $\mathrm{AgZn}_{3}$ phase. Insert is at lower magnification showing the surface partly covered by thick globular corrosion product. c)

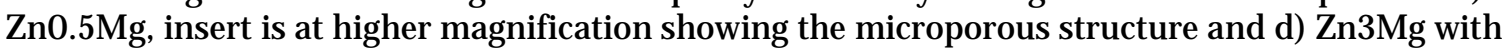
stratified corrosion product.

Figure 10: SEM images of sample surfaces after removal of corrosion product. a) cast Zn, insert is at lower magnification showing localized corrosion attacks, b) Zn4Ag, the dashed circles surrounding the preserved $\mathrm{AgZn}_{3}$ dendrites indicate areas significantly affected by microgalvanic corrosion c) $\mathrm{Zn} 0.5 \mathrm{Mg}$ and d) Zn3Mg with a layered morphology depleted of eutectic phase, the arrows indicate a selected micropore. 
Figure 11: SEM images of interface cross sections a) cast zinc with a dense homogeneous layer of corrosion products of approximately 10 micron in thickness. The white dashed line indicates the interface between the corrosion layer and the epoxy resin. b) $\mathrm{Zn} 4 \mathrm{Ag}$, the dashed line circles two AgZ $\mathrm{n}_{3}$ particles with the surrounding matrix completely removed by the penetration of the anodic corrosion c) $\mathrm{Zn} 0.5 \mathrm{Mg}$ with pits filled with corrosion product 10 micron deep into the substrate. The dashed line circles one pit. d) Zn3Mg with highly porous corrosion layer, $\sim 20$ micron thick. The dashed line indicates the interface between the metal and the corrosion product.

Figure 12: Illustration of the corrosion mechanism of a) Zn4Ag with selective dissolution of the Zn phase surrounding the $\mathrm{AgZn}_{3}$ phase. Increased precipitation of corrosion products will occur on areas with higher surface density of $\mathrm{AgZ} \mathrm{n}_{3}$ with an overall more anodic potential and increased cathodic reaction rates. b) Zn-Mg alloy with selective dissolution of the Mg rich phase. At short immersion times (hours) increased precipitation and agglomeration of corrosion product on the cathodic areas surrounding the anodic Zn-Mg phase (b, top image). At longer immersion times (days), most of the Mg rich phase is dissolved. Inclusions of denser corrosion product are formed on the earlier cathodic sites of increased precipitation (b, lower image). 


\section{Figures}

\section{Figure 1}
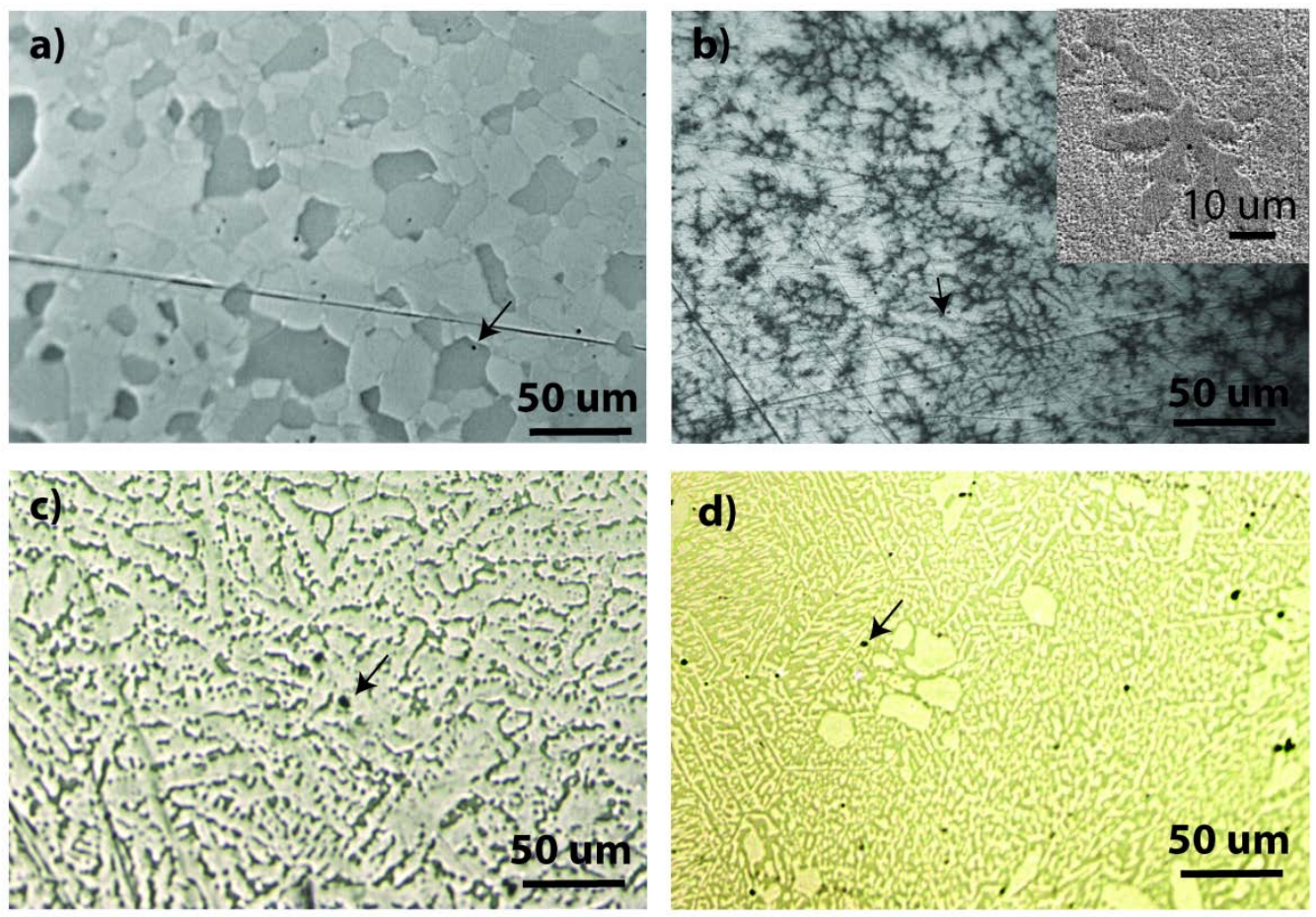

Figure 2

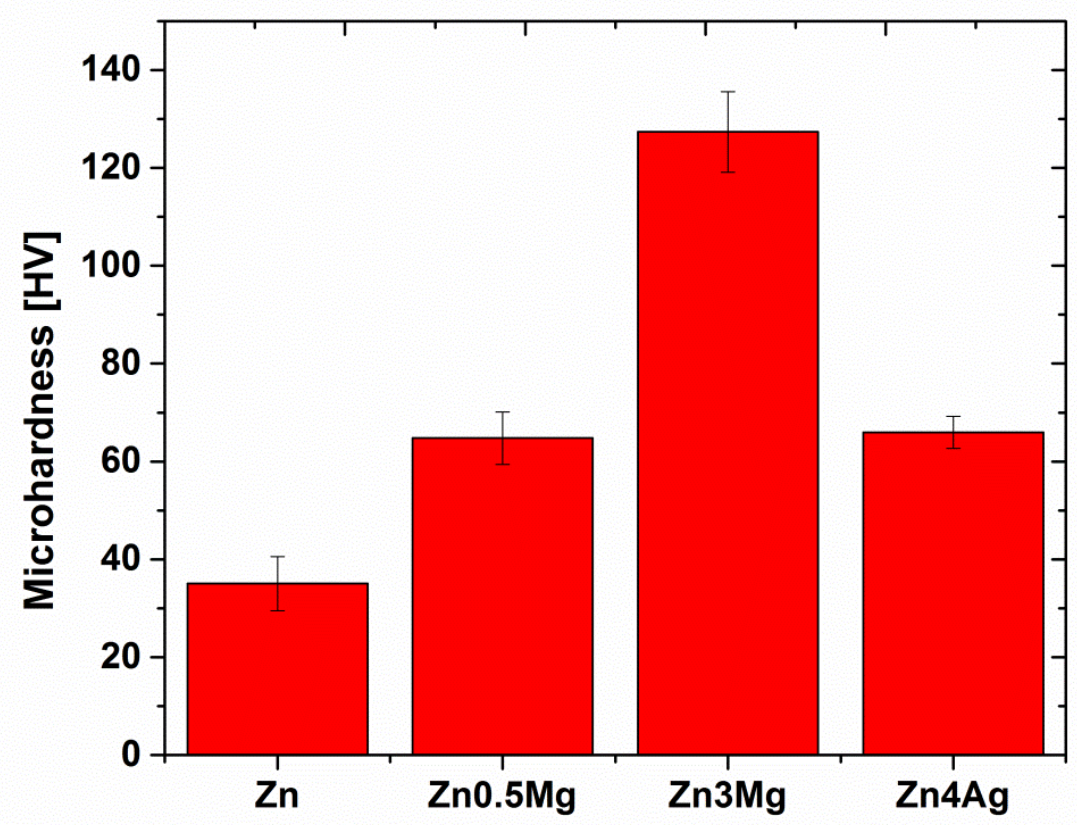


Figure 3
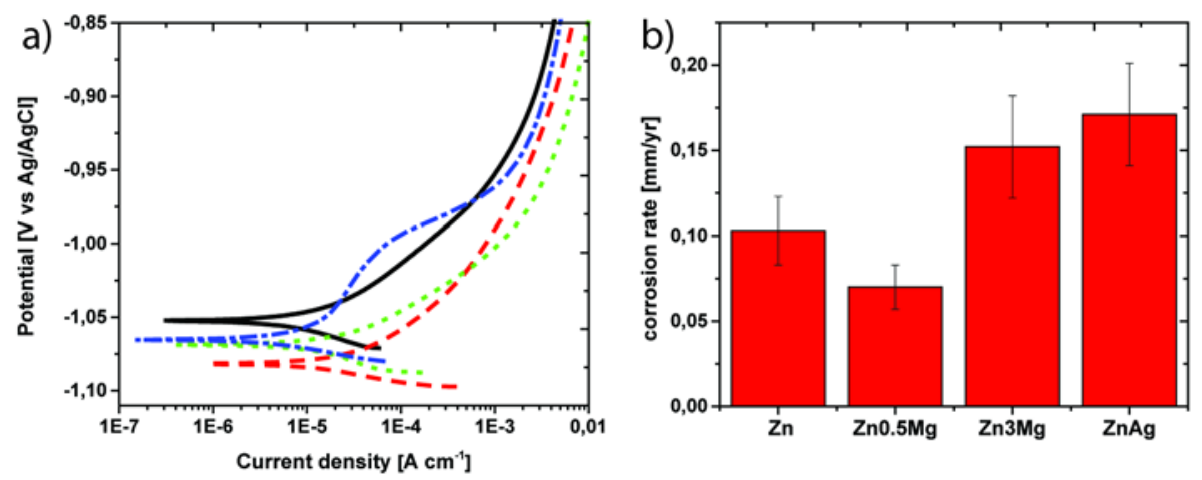

Figure 4

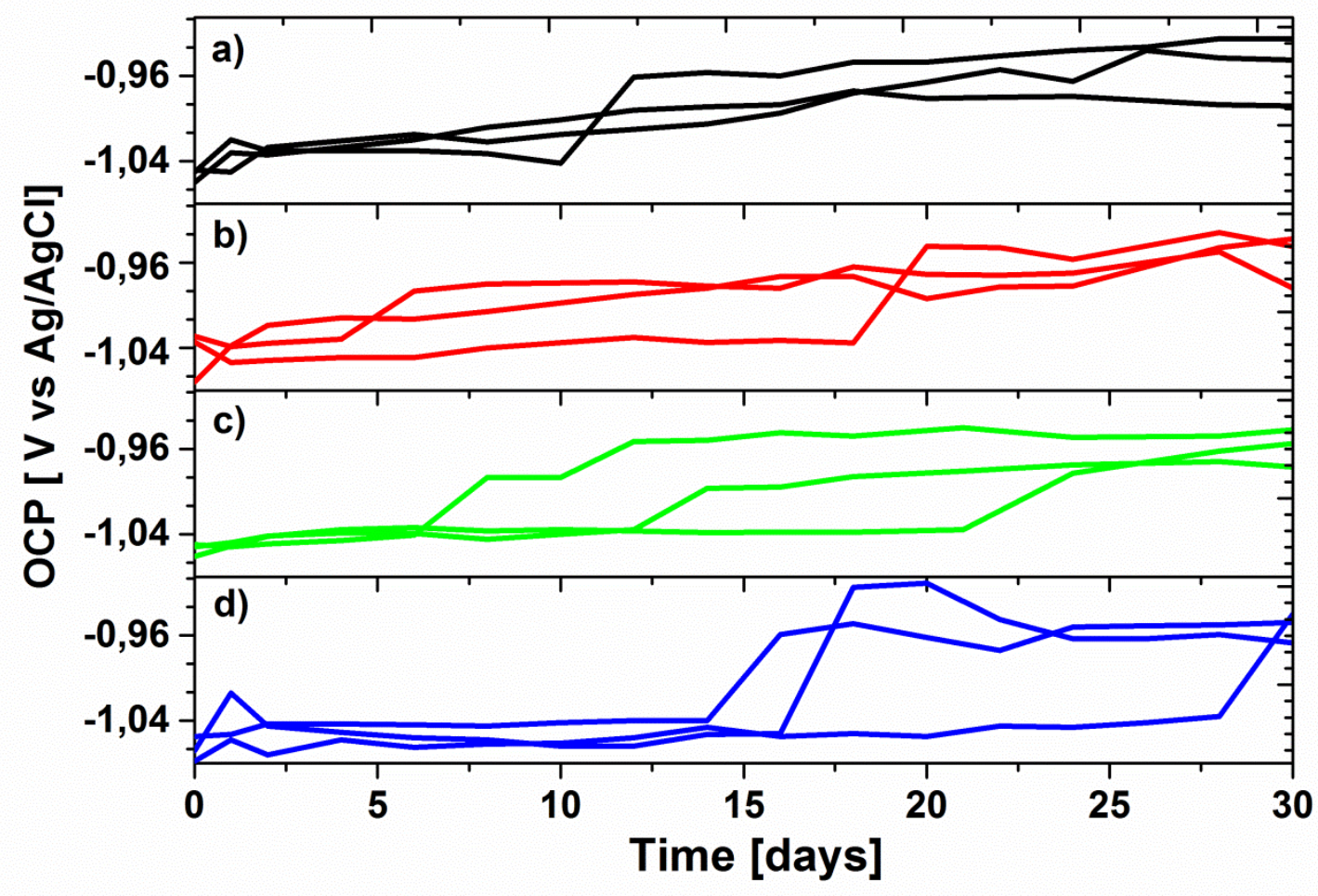


Figure 5
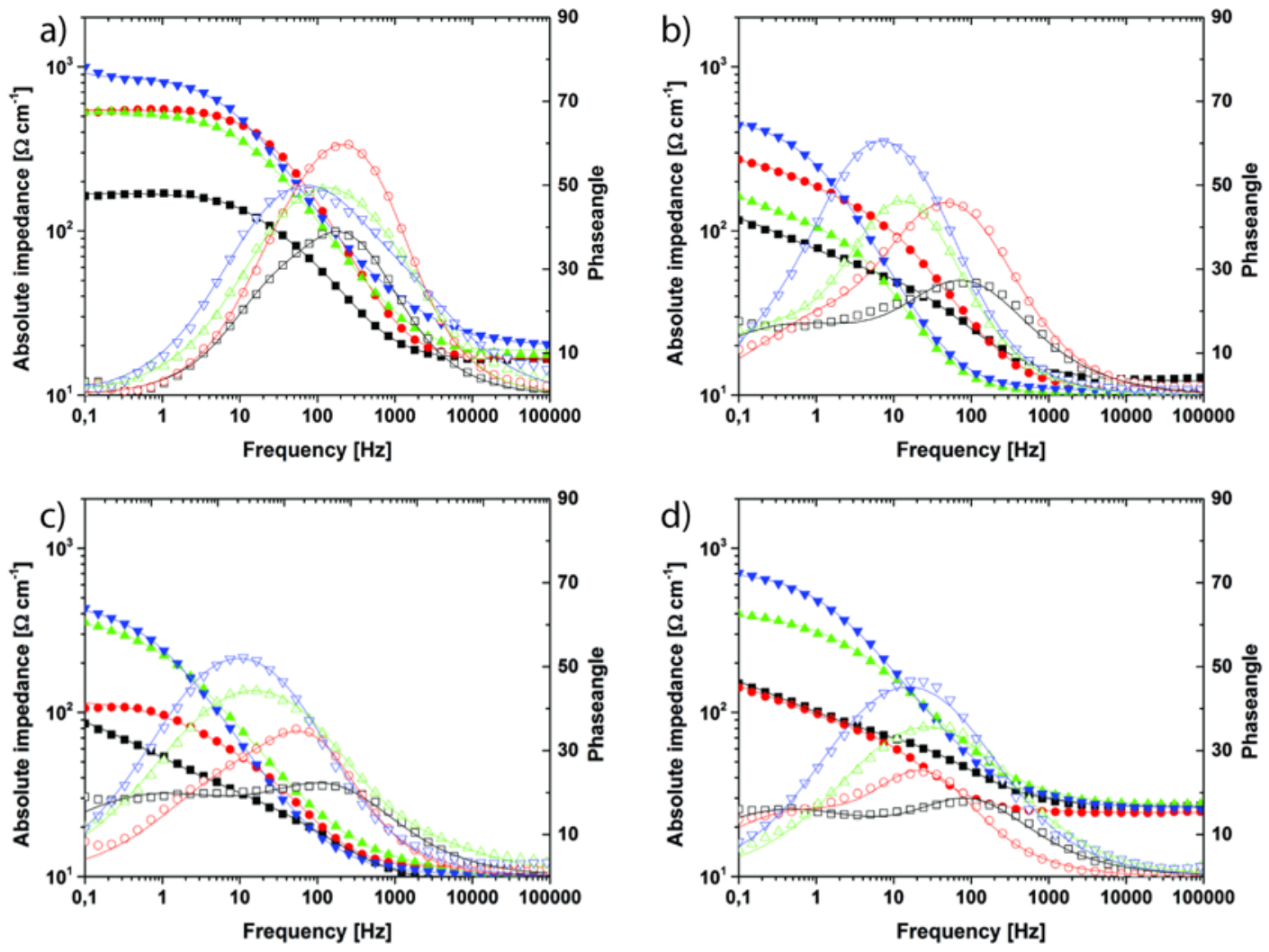

Figure 6
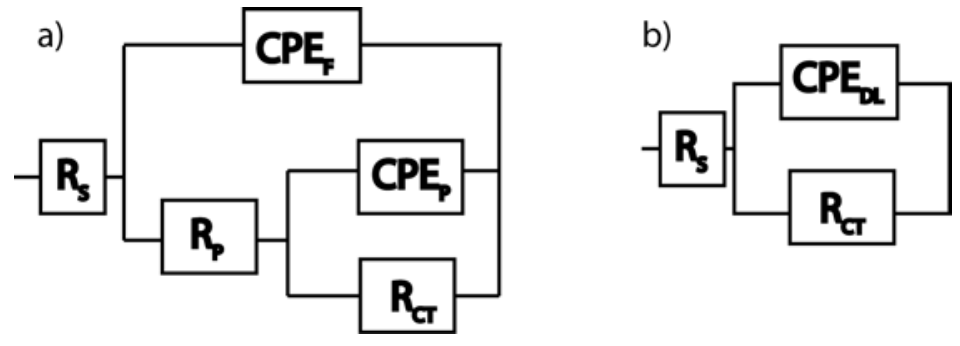
Figure 7

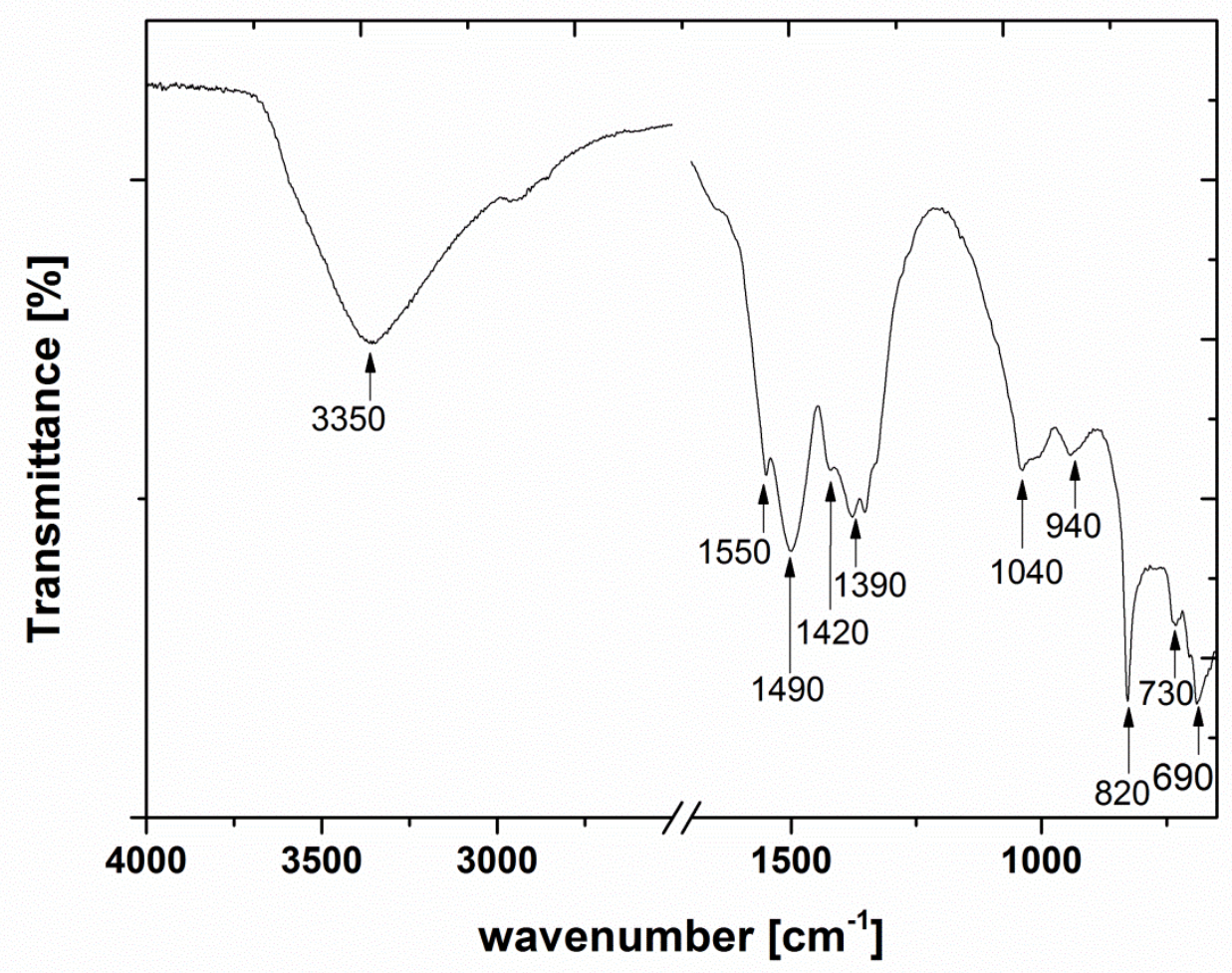

Figure 8
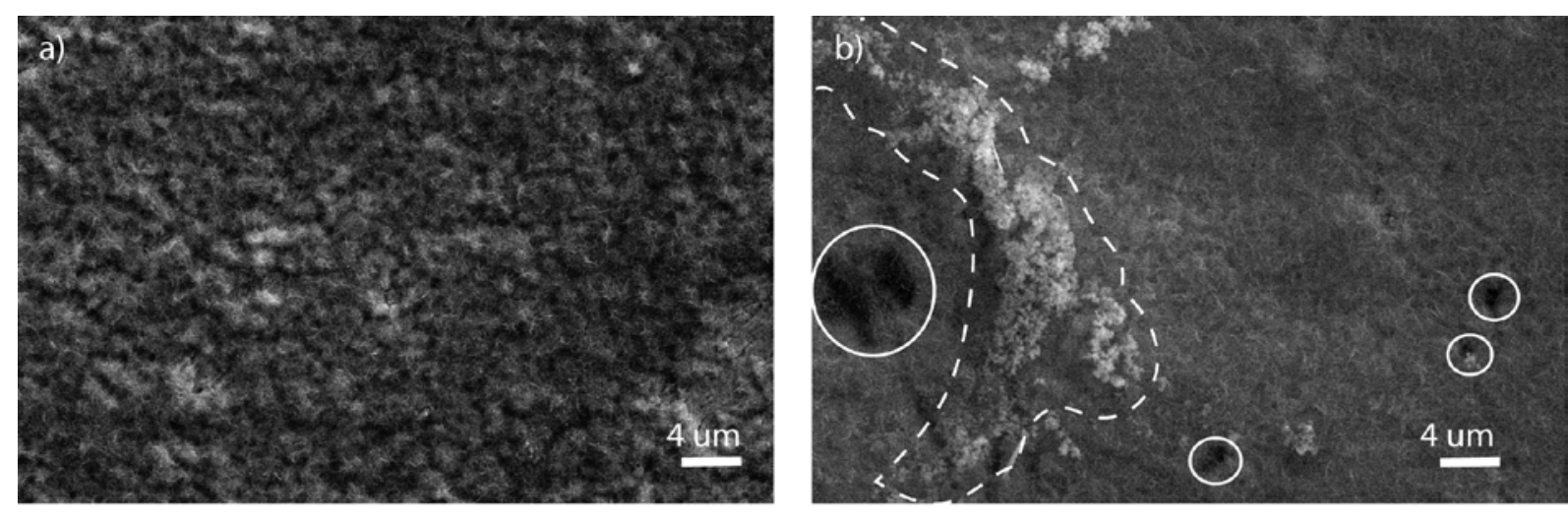


\section{Figure 9}
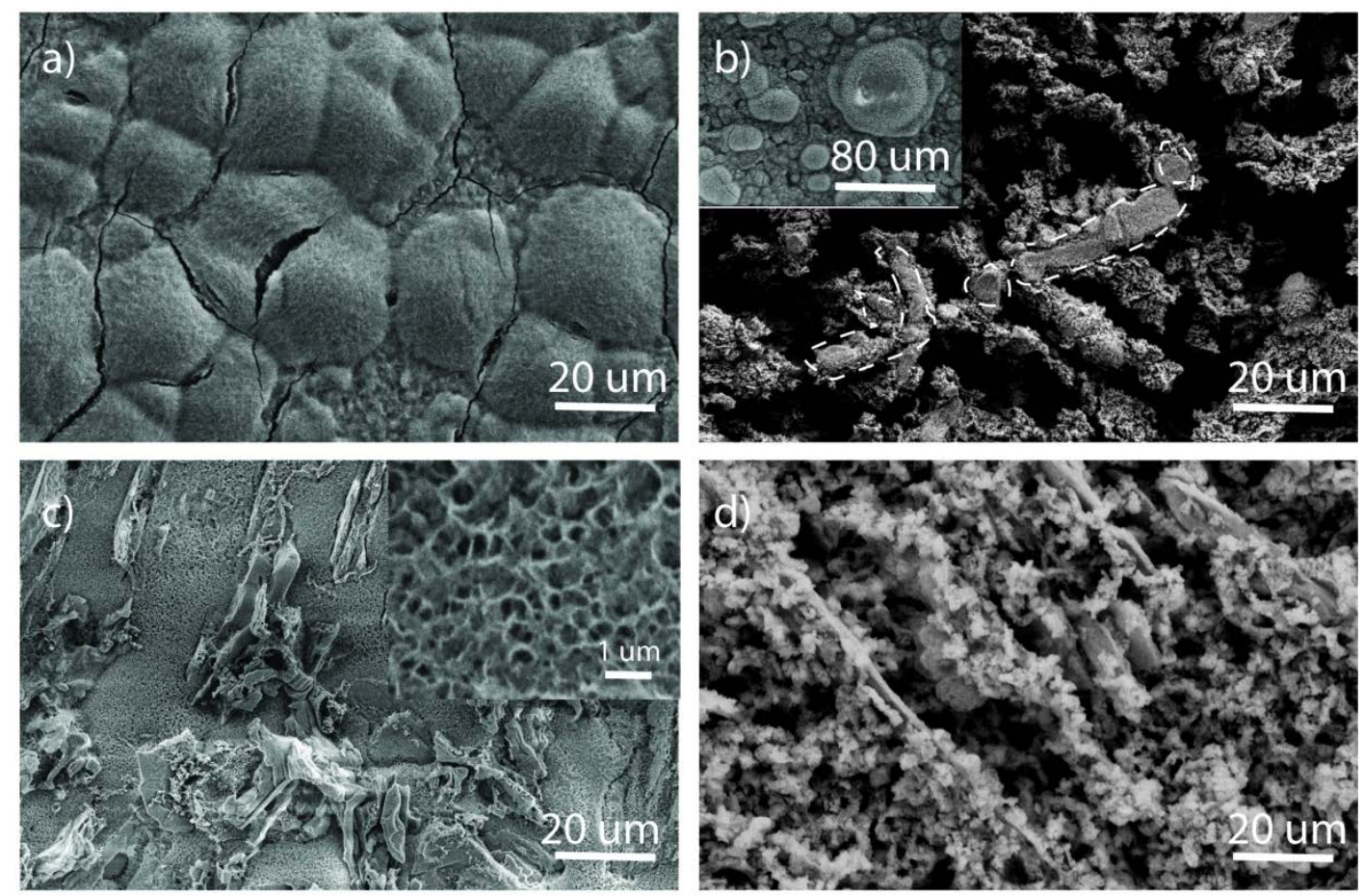

Figure 10
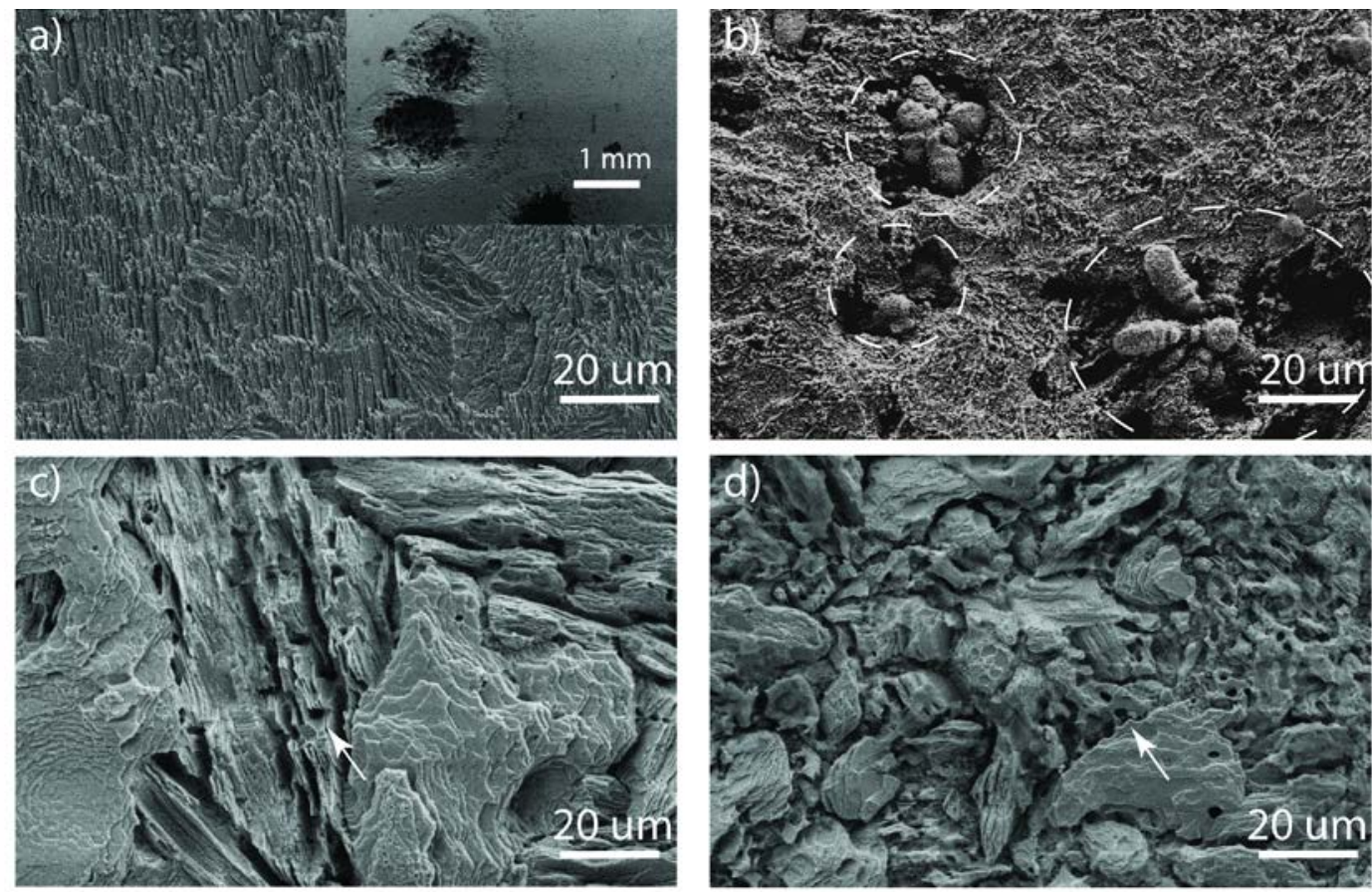
Figure 11
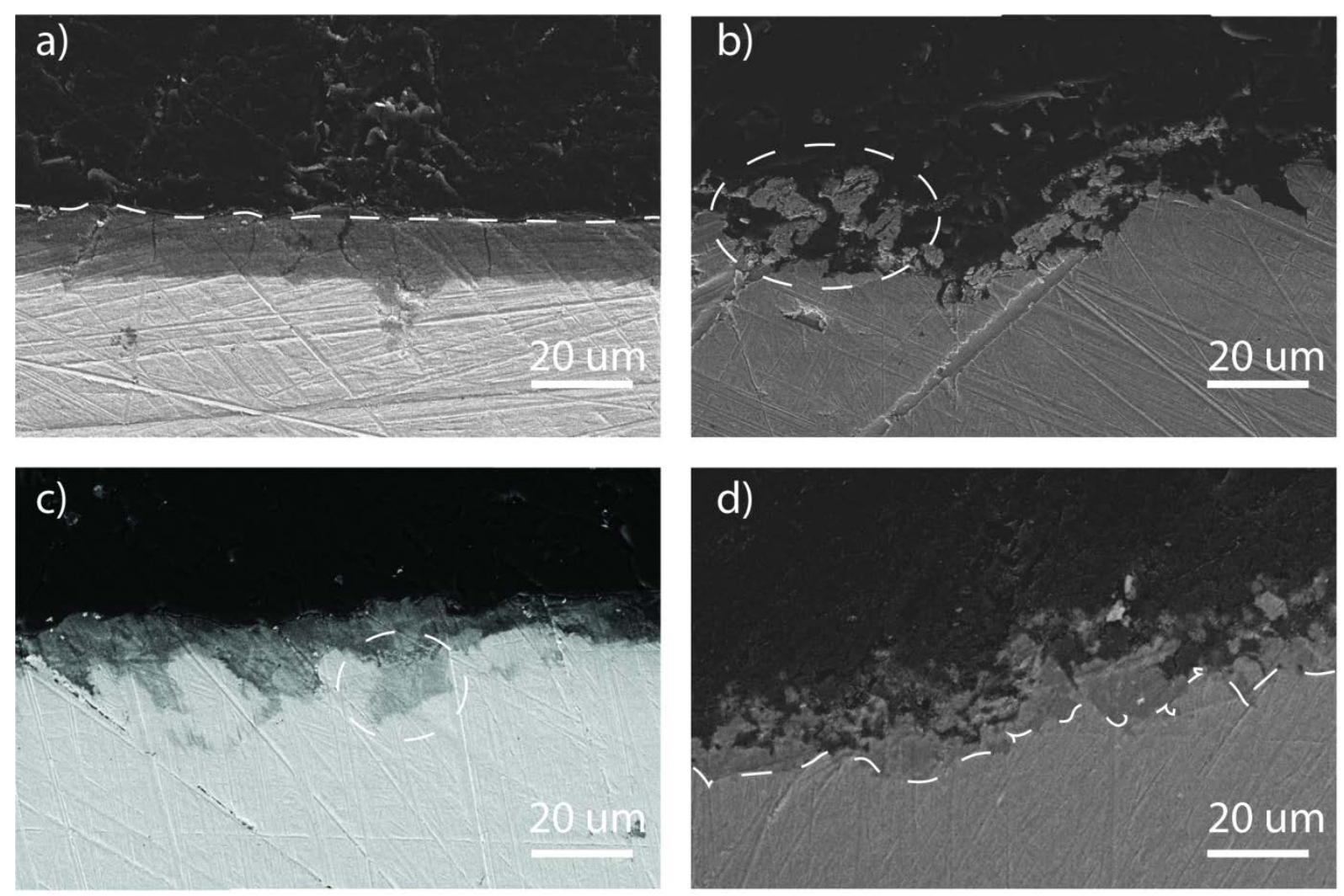

Figure 12 

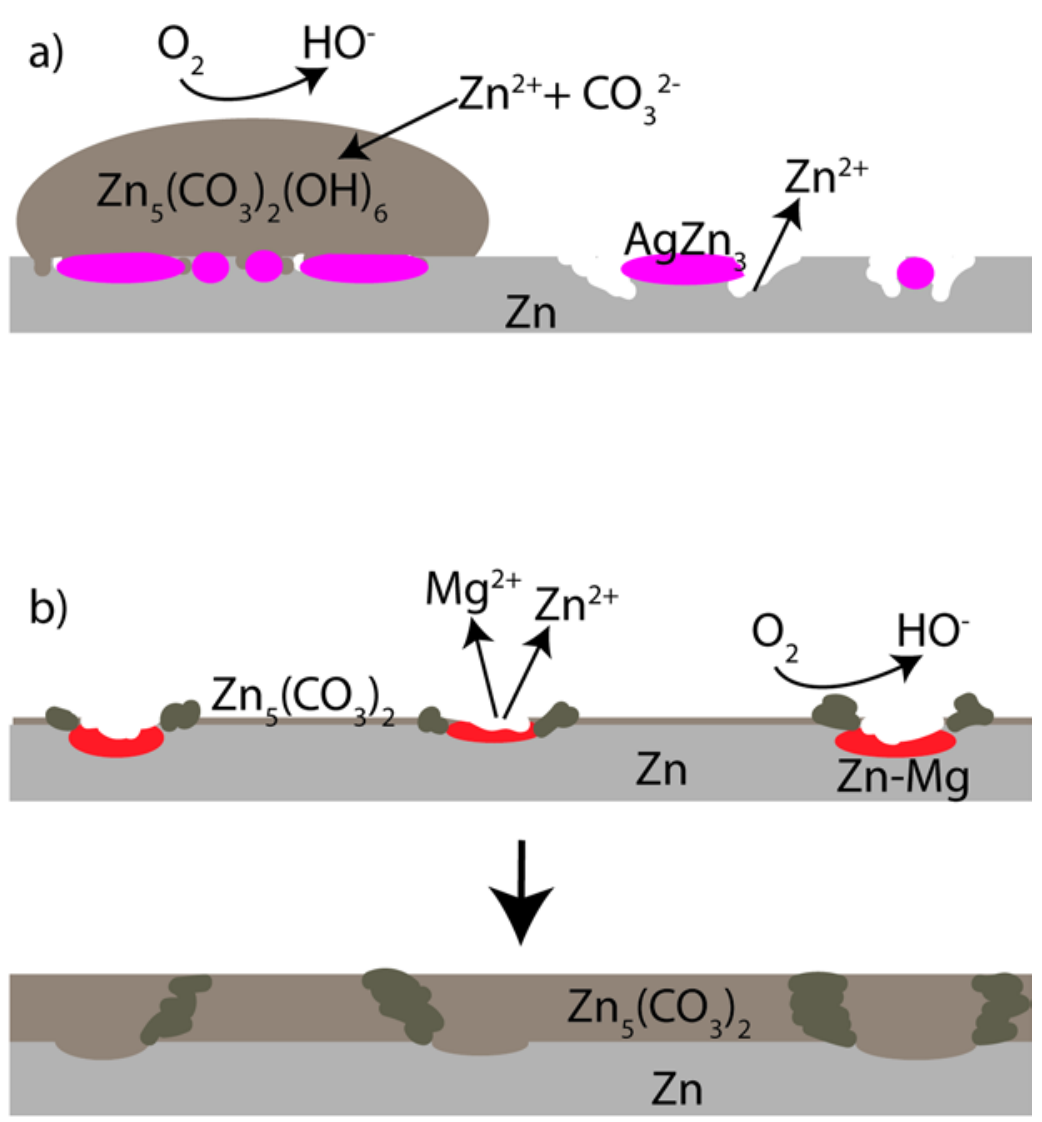